\title{
RESEARCH PAPER \\ Molluscicidal effects of saponin-rich plant extracts on the grey field slug
}

\author{
Diego González-Cruz, and Ricardo San Martín \\ Departamento de Ingeniería Química y Bioprocesos, Escuela de Ingeniería, Pontificia Universidad Católica \\ de Chile, Vicuña Mackena 4860. Macul, Santiago, Chile.
}

\begin{abstract}
D. González-Cruz, and R. San Martín. 2013. Molluscicidal effects of saponin-rich plant extracts on the grey field slug. Cien. Inv. Agr. 40(2): 341-349. Slug control is a major concern in crop fields because these mollusks consume and damage plants that are destined for human consumption and ornamentation. The grey field slug Deroceras reticulatum (Müller, 1774) is one of the most commonly occurring mollusks with agronomic importance, consuming up to $80 \%$ of the leaf surface of raps and other crops. The major difficulty in slug control is that the main products used for this purpose can also endanger non-target animals, such as pets and birds. New methods of control that are naturally based and environmental friendly are urgently required, both for the farmer who applies the product and for the final consumer. In this study, we analyzed the anti-molluscal activity of extracts from three plant with a high content of saponins: Camellia oleifera, Gleditsia amorphoides and Quillaja saponaria. Forced oral injection and histological analyses of the digestive system were performed to measure the effects of the plant extracts against slugs. All three extracts showed anti-feeding activity and toxicity against slugs when injected orally at a range of concentrations between 1 and $4 \% \mathrm{w} / \mathrm{w}$. All three extracts also damaged the gastric epithelium of the crop region of the slugs, suggesting that they show strong membranolytic properties in the digestive system of these mollusks. This study revealed novel natural compounds that can potentially be used in the control of grey field slugs. The data hereby presented could be useful in future comparative studies between other mollusks with agronomic importance.
\end{abstract}

Key words: Biopesticides, Camellia, Quillaja, Deroceras, saponins, slugs.

\section{Introduction}

Among terrestrial gastropods, some species of snails and slugs are highly harmful to a large variety of crops since antiquity, both in Chile

Received December 4, 2012. Accepted July 12, 2013. Corresponding author: degonzal@uc.cl and throughout the world. Slugs mainly live in humid environments and ingest various types of food, from plants to animal remains, consuming approximately half of their weight in one night (Kozłowski, 2012). The grey field slug, Deroceras reticulatum (Müller), is most likely the most widely occurring slug species. This species greatly endangers prairies and fields of crops destined for human and animal consumption, such as wheat, 
rape and canola (Islam, 2009). Slugs are also a problem in plant nurseries, where they may consume a wide variety of seedlings, ranging from vegetables to ornamental plants (Islam, 2009).

The major concern related to slug control is that the main product used for this purpose, metaldehyde, is also toxic to pets and non-target vertebrate species (Richardson et al., 2003). Despite fifty years of active research in this area, no environmentally friendly alternatives to metaldehyde have been commercially developed. Under this scenario, the search for new environmentally friendly and naturally formulated products is urgently required. Some novel approaches include the use of caffeine to control slugs and snails (Hollingsworth et al., 2003); however, this substance shows toxicity to other invertebrates.

Due to the above situation, in this work, we explore the use of saponins as potential candidates for developing safer molluscicides. Saponins are natural glycosides that exist in plants, chemically consisting of an aglycone (triterpenic or steroidal) bound to different sugars. This structure confers natural tensoactive properties on saponins such as anti-molluscal, anti-cholesterolic, anti-fungal and anti-carcinogenic characteristics, among others (Sparg et al., 2004; Stuardo and San Martín, 2008). The chemical structure of saponins determines their biological activity. While heterogeneous mixtures of saponins exist within the same plant (Hostettmann and Marston, 1995), a specific saponin or saponin mixture could be more adequate than other saponins to solve a specific problem.

The literature concerning the use of plant extracts with a high content of saponins for the control of terrestrial gastropods is scarce, as very few reports address this group of pests. The published reports are mainly related to egg control, feed deterrence, seed treatment and the formulation of baits. Regarding egg control, the use of quinoa husk extracts (Chenopodium quinoa Willd) for the control of $D$. reticulatum eggs has been reported (Iglesias et al., 2002). With respect to seed treatment, quinoa husk powder (Ch. quinoa) has been employed for the protection of seeds against D. reticulatum (Nijënstein and Ester, 1998). Concerning feeding deterrence, Saponaria officinalis extracts have been employed to combat Arion lusitanicus (Mabille) (Barone and Frank, 1999; Winder and Friedrich, 1996). Regarding baits, only one report has described the use of extracts from Aesculus hippocastenum, Koelreuteria paniculata and Primula elatior against A. lusitanicus (Winder and Friedrich, 1996). Our group has previously reported the effective use of Ch. quinoa saponins against the golden apple snail pest in rice (San Martín et al., 2008). The application of plant extracts with a high content of saponins could be a good means for controlling slugs because saponin residues have been demonstrated to be safe in foods and agronomic products in the US, EU and Japan. Furthermore, they present a minimal threat to the environment, being harmful to neither the farmer who applies them nor to plants.

In this study, extracts from three plant with a high content of saponins were analyzed: Gleditsia amorphoides (Griseb), Camellia oleifera (C. Abel) and Quillaja saponaria (Molina). The native Argentinean tree species G. amorphoides (Coronillo) produces seeds with a high content of triterpenic saponins. In C. oleifera, saponins are obtained from tea seeds, which are used extensively in Asia to produce edible oil. Saponins from the Chilean tree species Q. saponaria (Quillay) are widely employed in the formulation of natural foaming agents in food, beverages, cosmetics, vaccine adjuvants and food emulsifiers. The aim of this research is to investigate the molluscicidal effects of saponin-rich plant extracts from $G$. amorphoides, C. oleifera and $Q$. saponaria against the grey field slug, D. reticulatum. We analyzed the molluscicidal activity of the three plant extracts, examining their toxicity and anti-feeding activity when injected orally and performing histological analyses of the crop region of the digestive system of the slugs to analyze further damage. 


\section{Materials and methods}

\section{Collection and maintenance of slugs}

Wild slugs (D. reticulatum), were collected from March to June 2011 from sub-mountainous zones near Santa Sofía de lo Cañas, Santiago, Chile. The collections were performed at dawn from small crops in the area, and the specimens were then transported to the laboratory in small plastic boxes with sufficient lettuce for feeding. The slugs were maintained in plastic boxes $(26 \times 18 \times 12 \mathrm{~cm})$ with filter paper and moistened sand at the bottom to maintain a humid environment (Iglesias et al., 2002b). The boxes were placed in an incubation chamber (FOC 225E, VELP Scientifica, Italy), with the temperature regulated at $15^{\circ} \mathrm{C}$ and a relative humidity of $95 \%$. The slugs were maintained under light-dark cycles of 12:12 hours and fed with lettuce every day. The boxes were cleaned twice a week to maintain clean conditions, with a maximum of 25 slugs per box. The selection of slugs for each test was conducted at random and only after one week of acclimatization in the incubation chamber, to prevent the selection of weak specimens, which could interfere with the analysis. All animals were starved for 24 hours prior to the tests and were treated according to existing bioethical protocols.

\section{Forced oral injection}

Slugs with an average weight of $0.5 \mathrm{~g}$ (ranging from 0.4 to $0.6 \mathrm{~g}$ ) were anaesthetized via exposure to an atmosphere of carbon dioxide gas for $20 \mathrm{~min}$ in a sealed plastic box with input and output tubes, allowing the gas to flow through the box. Subsequently, the slugs were placed under a magnifier glass to carry out oral injection with different plant extracts to analyze their oral toxicity. The tested products were extracts from the following three plant species: Camellia oleifera (Chinese tea extract, 40\% w/w saponins, obtained from China), Quillaja saponaria (a native tree species from Chile, commercial name QP1000,
20\% w/w saponins; Natural Response, Quilpué, Chile) and Gleditsia amorphoides (a native tree species from Argentina, commercial name CP Ultra, 23\% w/w saponins; Natural Response). Each product was tested at increasing saponin concentrations ( $0,1,2$ and $4 \% \mathrm{w} / \mathrm{w}$, corresponding approximately to a dose of $0.2,0.4$ and $0.8 \mathrm{mg} / \mathrm{g}$ slug b.w., respectively). Ten slugs were tested per dosage, with three repetitions conducted for each concentration.

Each concentration of the plant extracts was added to a warm $1.5 \% \mathrm{w} / \mathrm{w}$ agar solution, which gelled upon cooling prior to forced oral injection (Henderson, 1969). The applied method consisted of the injection of the toxic gel into the buccal cavity of the slugs, through a $50 \mu$ Hamilton syringe. A $10 \mu \mathrm{l}$ aliquot of the agar solutions was injected into the mouth of anaesthetized slugs. Once the slugs had awoken from anesthesia (approx. 30 minutes later), they were immediately passed between two small foam-rubber rollers, starting from the mouth, extending as far back as the anterior margin of the mantle. The rollers were in contact with each other, but under no pressure, leaving the slugs unconstrained and stimulating them to swallow the gel. Ten control slugs per repetition were prepared following the same method, but with the injected agar solution containing no saponins. Subsequently, the treated and control slugs were placed individually in Petri dishes containing filter paper soaked with $2 \mathrm{ml}$ of distilled water and a piece of lettuce with a size of $20 \times 20 \mathrm{~mm}$. The Petri dishes were then incubated in an incubation chamber with a regulated temperature (FOC 225E, VELP Scientifica) and with humidity provided by moistened filter paper in the dish $(95 \% \mathrm{RT})$. The slugs were evaluated to determine whether they were alive and whether they consumed the lettuce every 24 hours for 5 days. The lettuce was replaced every day to check the feeding activity of the slugs. Day 3 was selected arbitrarily to perform the toxicological analysis. Statistical analyses were conducted using Turkey's multiple comparison tests for all of the forced oral injection experiments. 


\section{Histological analyses}

The crop region of the digestive tubes of the slugs injected with G. amorphoides, $Q$. saponaria and C. oleifera was analyzed to evaluate the damage caused by the saponin-rich plant extracts. A $4 \%$ $\mathrm{w} / \mathrm{w}$ saponin concentration was injected into the slugs to analyze the resultant acute damage to the crop region. The type of saponins and saponin concentration were selected based on the results of the mortality analyses (see Results and Discussion). Slugs were fixed five hours after the forced oral injection, as it is reported in literature with histological studies in slugs injected with metaldehyde (Triebskorn et al., 1998). Aliquots of $10 \mu \mathrm{l}$ were injected into the mouth of the slugs, using five specimens per control and five per treatment. Control slugs were only injected with agar solution.

Five hours after forced oral injection, the slugs were fixed in $3 \%$ glutaraldehyde in $0.1 \mathrm{M}$ sodium cacodilate buffer for six hours at room temperature and then washed in $0.1 \mathrm{M}$ sodium cacodilate buffer, $\mathrm{pH} 7.2$, for 18 hours at $4^{\circ} \mathrm{C}$. The samples were post-fixed with a $1 \%$ osmium tetroxide solution for 90 minutes. After washing the samples for 30 minutes in distilled water, they were dehydrated through a battery of 50, 70, 95 and $100 \%$ acetone and then preincubated in epon:acetone 1:1 overnight. Finally, the samples were placed in $100 \%$ epon and left to polymerize for 24 hours at $60^{\circ} \mathrm{C}$. Semi-thin sections $(1 \mathrm{~m})$ were obtained using a Sorvall MT2B ultramicrotome and placed on slides treated with silane. The slides were finally dyed in toluidine blue with $2 \%$ borax for 20 seconds and observed under a light microscope.

\section{Results and discussion}

\section{Forced oral injections}

Following injection, all slugs were able to recover from anesthesia after approximately 30 minutes. Table 1 shows that the slugs injected with G. amorphoides, C. oleifera and Q. saponaria presented clear signs of feeding impairment under all of the tested doses compared to the control group $(\mathrm{P} \leq 0.05)$. A dose of $1 \% \mathrm{w} / \mathrm{w}$ Q. saponaria (approx. $0.8 \mathrm{mg} / \mathrm{g}$ b.w. slug) was sufficient to completely stop feeding, even without significant mortality being observed compared to the control group. A dose of $1 \% \mathrm{w} / \mathrm{w}$ G. amorphoides and C. oleifera also stopped feeding but significantly increased mortality compared to the control group. All of the control slugs were able to feed normally, while the slugs injected with the plant extracts reacted with abundant mucus secretions from their bodies.

All three plant extracts showed toxic effects against the slugs, beyond their anti-feeding activities. When administered orally, significant mortality was associated with $G$. amorphoides and $C$. oleifera treatment, starting at a concentration of $1 \%$ compared to the control group $(\mathrm{P} \leq 0.05)$. $Q$. saponaria caused significant mortality compared to the control group $(\mathrm{P} \leq 0.05)$ starting at a $2 \%$ concentration. Furthermore, $100 \%$ mortality was observed following treatment with a $4 \%$ concentration of G. amorphoides, while Q. saponaria and $C$. oleifera resulted in significant mortality, above $80 \%$, at the same concentration. Saponins have been demonstrated to be effective compounds for combating other mollusks, such as the golden apple snail (GAS) (Hostettmann and Marston, 1995; San Martin, 2006; San Martin et al., 2009; San Martín et al., 2008). Therefore, the feeding impairment and mortality observed against slugs could be directly related to the dose of saponins injected (approx. $0.2 \mathrm{mg} / \mathrm{g}$ b.w. for $1 \% \mathrm{w} / \mathrm{w}$ ). All of the plant extracts tested here contained high concentrations of triterpenic saponins, which have also been reported to be effective molluscicides (Hostettmann and Marston, 1995; San Martin, 2006; San Martin et al., 2009).

\section{Histology of the crop region}

To further examine the toxicity of $C$. oleifera, Q. saponaria and G. amorphoides against slugs, histological analyses were performed on the crop 
Table 1. Average mortality and feeding $(\% \pm$ standard error) of D. reticulatum following forced oral injection with plant extracts at different concentrations on day 3 .

\begin{tabular}{lccc}
\hline Plant extract & $\begin{array}{c}\text { Saponin concentrations, } \\
\% \text { w/w }\end{array}$ & Mortality, \% & Feeding, $\%$ \\
\hline G. amorphoides & 0 (Control) & $13.3 \pm 1.8 \mathrm{a}$ & $54.3 \pm 3.7$ \\
1 & $53.3 \pm 1.8 \mathrm{~b}$ & $0 \pm 0.0$ \\
2 & $70 \pm 5.5 \mathrm{~b}$ & $0 \pm 0.0$ \\
4 & $100 \pm 0 \mathrm{c}$ & $0 \pm 0.0$
\end{tabular}

Q. saponaria

$\begin{array}{ccc}0 \text { (Control) } & 10 \pm 3.2 \mathrm{a} & 83.3 \pm 1.8 \\ 1 & 26.7 \pm 1.8 \mathrm{a} & 0 \pm 0.0 \\ 2 & 70 \pm 6.3 \mathrm{~b} & 0 \pm 0.0 \\ 4 & 83.3 \pm 1.8 \mathrm{~b} & 0 \pm 0.0\end{array}$

C. oleifera

$\begin{array}{ccc}0 \text { (Control) } & 6.7 \pm 1.8 \mathrm{a} & 73.3 \pm 8 \\ 1 & 70 \pm 5.5 \mathrm{~b} & 0 \pm 0.0 \\ 2 & 83.3 \pm 9.1 \mathrm{~b} & 0 \pm 0.0 \\ 4 & 86.7 \pm 4.8 \mathrm{~b} & 0 \pm 0.0\end{array}$

Different small letters between treatments within a column indicate significant differences between concentrations, according to Tukey tests $(\mathrm{P} \leq 0.05)$.

region of the gastric system. The acute dose of saponins injected $(4 \% \mathrm{w} / \mathrm{w}$, approx. $0.8 \mathrm{mg} / \mathrm{g})$ was sufficient to kill the slugs within 24 hours. Immediately after the slugs were injected with plant extracts, they secreted abundant mucous from their bodies, showing clear signs of intoxication.

All three plants extracts tested (Q. saponaria, $G$. amorphoides and C. oleifera) damaged the crop epithelium in the digestive system of the slugs when administered orally. Figure 1 shows representative slides of the crop regions of all of the analyzed slugs. Samples from control slugs are shown in sub-boxes $\mathrm{A}, \mathrm{B}$ and $\mathrm{C}$ (400X), while specimens from treated slugs are shown in D-I (100X). The sub-boxes in Figure 1 correspond to treatment with extracts from G. amorphoides $(\mathrm{D}, \mathrm{G})$, Q saponaria $(\mathrm{E}, \mathrm{H})$ and C. oleifera (F, I). Boxes A, B and C show the normal gastric epithelium of the control slugs (similar to slugs that were not treated with agar), while boxes D-I show clear signs of epithelium shortening and, in some cases, ulceration (Figure 1, arrow in E).
The effects of saponins on the digestive system depend on the source and structure of the saponins tested. Our data strongly suggest that saponins from Q. saponaria, G. amorphoides and C. oleifera damage the gastric epithelium of slugs. In contrast, the literature indicates that plant extracts from C. sinensis, $Q$. saponaria, Paris polyphylla and Pteleopsis suberosa are gastroprotective against lesions induced by ethanol and indomethacin in rats (Yoshikawa et al., 2005; Yoshikawa et al., 2007). This finding likely suggests that some saponins display different effects in different species, working as gastroprotective agents in some species, such as rats, and inducing gastric damage in slugs.

The mechanism underlying the feeding impairment observed in mollusks exposed to molluscicides is not fully understood, but it could apparently be strongly related to damage to the gastric system or even impacts on the nervous system, as some authors have suggested (Zaldibar et al., 2007). The cellular mechanism of the action of saponins leading to epithelium fragmentation and ulcer- 


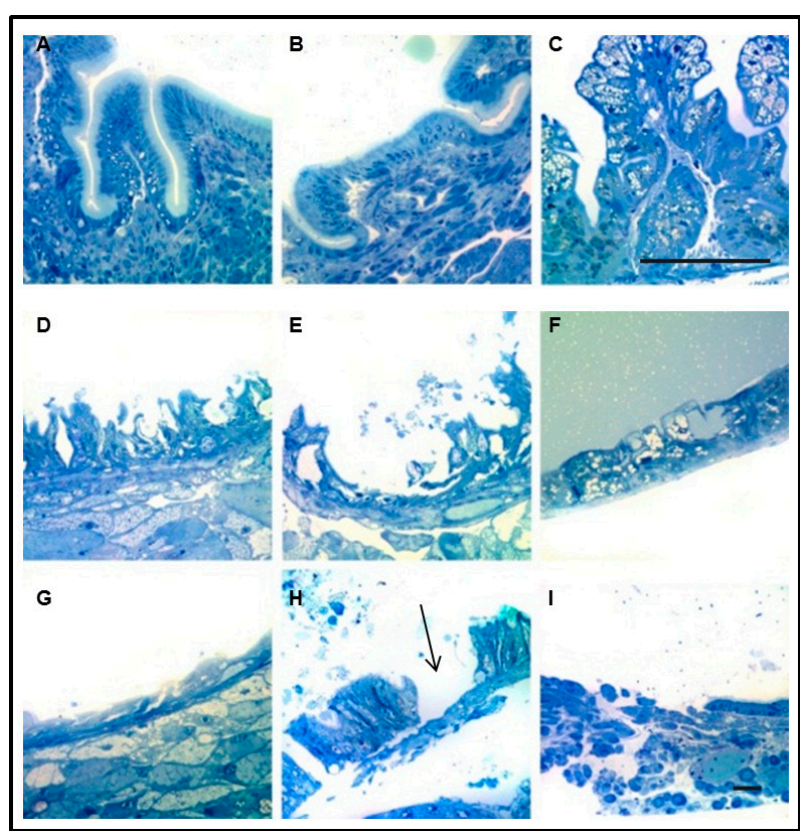

Figure 1. Representative semithin sections of the crop epithelium of D. reticulatum. Controls are shown in A, B and C (400X, bar equals to $100 \mathrm{~mm}$ ), corresponding to G. amorphoides, Q. saponaria and C. oleifera, respectively. Treated slugs are shown in D-I (100, bar equals to $100 \mathrm{~mm})$, corresponding to $G$. amorphoides $(\mathrm{D}, \mathrm{G})$, Q. saponaria $(\mathrm{E}, \mathrm{H})$ and $C$. oleifera $(\mathrm{F}, \mathrm{I})$. An example of the observed ulceration is indicated with an arrow in $\mathrm{H}$.

ation is not completely clear. There is evidence of permeabilization of the cellular membranes of erythrocytes through the complexation of saponins with cholesterol, thus affecting the structure of the cellular membrane (Baumann et al., 2000). Another proposed mechanism is interaction of saponins with aquaporins, leading to the cellular rupture (Winter, 1994). Other authors claim that the formation of membrane pores by triterpenic saponins occurs in a cholesterol-independent manner, but it also depends greatly on the saponin structure (Melzig et al., 2001). According to the literature, the effects of saponins on the digestive system are diverse because they can act both as protectors against ulcerative lesions and as destructors of the cellular membrane. Saponins have also been described as enhancers of gastric permeability and natural enhancers of tumor cell apoptosis (Chow et al., 2002; Zhong et al., 2004), supporting the notion that the biological effects of saponins vary among species.

Regarding the availability of plant extracts from C. oleifera, $Q$. saponaria and G. amorphoides, it is important to note that they are all obtained through other sub-processes, resulting in high availability of these saponin products at a low cost. For example, C. oleifera extracts come from seeds that are mainly destined for the production of edible oil. In this process, a sub-product is obtained from the pressing of the seeds in the form of a crushed cake, which has a high content of saponins. The main saponins from C. oleifera are theasaponins (Yoshikawa et al., 2007), which possess high molluscicidal, fungicidal and piscicidal properties (Tomita et al., 2000).

G. amorphoides extracts are obtained from the seeds of the Argentinean Coronillo tree, which is mainly destined for the production of natural gum and generates a sub-product with a high content of saponins. The external hull of the fruit contains triterpenic saponins that are extracted and sold as a liquid concentrate or powder product. The main use of Coronillo saponins is as surfactants in the formulation of glyphosate, which is widely applied among soy cultivars in Argentina. This product is available commercially on the Internet 
(http://naturegum.com/), and these saponins are approved by Resolution No. 53/76 in Argentina as a safe additive in food.

Q. saponaria extracts are obtained from aqueous extracts of bark or whole wood acquired from pruning operations conducted in existing forests (San Martin and Briones, 2000), resulting in a well-established, inexpensive process.

All the processes described above could improve the utilization of natural products with a very low commercial value, by employing them to control important pests, such as slugs, under field conditions. Additionally, all of the tested plant extracts have been approved as components of edible items, so they do not present a threat in relation to human consumption (US Code of Federal Regulations, 2001).

We conclude that plant extracts with a high content of saponins could be useful for the control of slugs because they show strong molluscicidal effects against these mollusks. Cheap sources of saponins from plants can be found in every country, which could lead to the future development of natural alternatives to synthetic compounds such as metaldehyde. Additionally, a great variety of saponins are allowed in edible items because they are permitted as residues in crops. The insights provided by this work could lead to the use of environmentally friendly pesticides against slugs and other mollusks, resulting in the improved use of inexpensive subproducts from saponin-rich plant extracts, which are often destined to waste. However, commercial applications will only arise if saponins are successfully formulated as palatable baits and if the resultant effects on slugs replicate what has been observed in this work. This work is part of our current research efforts.

\section{Acknowledgments}

We thank Alejandro Munizaga for his help with the histological analysis (Facultad de Ciencias Biológicas, Pontificia Universidad de Chile).

\section{Resumen}

D. González-Cruz y R. San Martín. 2013. Efecto molusquicida de extractos naturales ricos en saponinas en contra de la babosa gris de jardín. Cien. Inv. Agr. 40(2): 341-349. El control de babosas en cultivares es de gran importancia agronómica, debido a que éstas comen y dañan plantas destinadas tanto al consumo humano como a ornamentación. La babosa gris de jardín (Deroceras reticulatum) es uno de los moluscos más frecuentes y dañinos, debido a su capacidad de comer hasta el $80 \%$ de la superficie foliar en cultivos como el raps y canola. El mayor problema consiste en que los principales productos usados en su control, como el metaldehído y metiocarb, no son permitidos como residuos agrícolas en muchos países. Estos productos además amenazan fuertemente a organismos no objetivos como mascotas y pájaros. Nuevos métodos de control basados en compuestos naturales y amigables con el medio ambiente son requeridos urgentemente, tanto para el operario que aplica el producto como para el consumidor final. En este estudio se analizó la actividad molusquicida de tres extractos de plantas ricos en saponinas: Camellia oleifera, Gleditsia amorphoides y Quillaja saponaria. Se realizaron estudios de inyección oral forzosa e histología del sistema digestivo, con el fin de estudiar los efectos de estos extractos sobre el sistema digestivo de las babosas. Los tres extractos mostraron actividad anti-alimentaria y ser tóxicos contra las babosas cuando fueron inyectados oralmente, en un rango de concentración entre 1 y $4 \%$ p/p. Los tres extractos, 
además dañaron el epitelio gástrico de la región del buche, sugiriendo fuertes propiedades membranolíticas. El presente estudio muestra nuevos compuestos de origen natural que podrían ser ocupados para el control de babosas. Además, Los datos aquí presentados pueden ser útiles para futuros estudios comparativos en otras especies de moluscos de importancia agronómica.

Palabras clave: Babosas, biopesticidas, Camellia, Quillaja, Deroceras, saponinas.

\section{References}

Barone, M., and T. Frank. 1999. Effects of plant extracts on the feeding behaviour of the slug Arion lusitanicus. Annals of Applied Biology 134:341345.

Baumann, E., G. Stoya, A.Volkner, W. Richter, C. Lemke, and W. Linss. 2000. Hemolysis of human erythrocytes with saponin affects the membrane structure. Acta Histochemica 102:21-35.

Chow, L., J. Tang, I. Teo, C. Chui, F. Lau, T. Leung, G. Cheng, R. Wong, I. Wong, and K. Tsang. 2002. Antiproliferative Activity of the Extract of Gleditsia sinensis Fruit on Human Solid Tumour Cell Lines. Chemotherapy 48:303-308.

Henderson, I. 1969. A laboratory method for assessing the toxicity of stomach poisons to slugs. Annals of Applied Biology 63:167-171.

Hollingsworth, R., J. Armstrong, and E. Campbell. 2003. Caffeine as a novel toxicant for slugs and snails. Annals of Applied Biology142:91-97.

Hostettmann, K., and A. Marston. 1995. Saponins. Cambridge University Press. Cambridge, United Kingdom.

Iglesias, J., J. Castillejo, and A. Ester. 2002. Laboratory evaluation of potential molluscicides for the control of eggs of the pest slug Deroceras reticulatum (Muller)(Pulmonata: Limacidae). International Journal of Pest Management 48:19-23.

Islam, M.S. 2009. Impacts of food diversity on some reproductive attributes in the gray field slug Deroceras reticulatum (Müller). Journal of BioScience 15:15-21.

Kozłowski, J. 2012. The significance of alien and invasive slug species for plant communities in agrocenoses. Journal of Plant Protection Research 52:67-76.
Melzig, M.F., G. Bader, and R. Loose. 2001. Investigations of the mechanism of membrane activity of selected triterpenoid saponins. Planta Med. $67: 43-48$

Nijënstein, J.H., and A. Ester. 1998. Phytotoxicity and control of the field slug Deroceras reticulatum by seed applied pesticides in wheat, barley and perennial ryegrass. Seed Science and Technology 26:501-513.

Richardson, J.A., S.L. Welch, S.M. Gwaltney-Brant, J.D Huffman, andM.E. Rosendale. 2003. Metaldehyde toxicoses in dogs. Compendium 25:376-380.

San Martin, R. 2006. Recent developments on the use of botanical molluscicides against Golden apple snails (Pomacea canaliculata). In: Joshi, R.C. and L.S. Sebastian (eds.). Global advances in ecology and management of golden apple snails. Neur Ecija, Philippines: PhilRice. p. 393-403.

San Martin, R., R. Briones. 2000. Quality control of commercial quillaja (Quillaja saponaria Molina) extracts by reverse phase HPLC. Journal of the Science of Food and Agriculture 80:2063-2068.

San Martin, R., C. Gelmi, J. de Oliveira, J. Galo, and H. Pranto. 2009. Use of a saponin based molluscicide to control Pomacea canaliculata snails in Southern Brazil. Natural Product Communications 4:1327-1330.

San Martín, R., K. Ndjoko, and K. Hostettmann. 2008. Novel molluscicide against Pomacea canaliculata based on quinoa (Chenopodium quinoa) saponins. Crop Protection 27:310-319.

Stuardo, M., and R. San Martín. 2008. Antifungal properties of quinoa (Chenopodium quinoa Willd) alkali treated saponins against Botrytis cinerea. Industrial Crops \& Products 27:296-302.

Tomita, M., S. Yamamoto, K. Yamaguchi, H. Ohigashi, T. Yagi, K. Kohata, and J. Berden. 2000. 
Theasaponin E1 destroys the salt tolerance of yeasts. Journal of Bioscience and Bioengineering 90:637-642.

Triebskorn, R., K. Christensen, G. Heim. 1998. Effects of orally and dermally applied metaldehyde on mucus cells of slugs (Deroceras reticulatum) depending on temperature and duration of exposure. Journal of Molluscan Studies 64:467-487.

US Code of Federal Regulations. http://www.archives.gov/open/dataset-cfr.html

Winder, O., C. Friedrich, 1996. The effect of some plant saponins on Arion lusitanicus (Gastropoda:Arionidae) in Laboratory Experiments. Zool. Beitr. 37:185-197.

Winter, W., 1994. Mechanism of saponin induced red cell hemolysis: Evidence for the involvement of aquaporin CHIP28. Blood 84:445.

Yoshikawa, M., T. Morikawa, N. Li, A. Nagatomo, X. Li, H. Matsuda. 2005. Bioactive Saponins and Glycosides. XXIII. Triterpene Saponins with Gastroprotective Effect from the Seeds of Camellia sinensis-Theasaponins E 3, E 4, E 5, E 6, and E 7-. Chemical and Pharmaceutical Bulletin 53:1559-1564.

Yoshikawa, M., T. Morikawa, S. Nakamura, N. Li, X. Li, H. Matsuda. 2007. Bioactive saponins and glycosides. XXV. Acylated oleanane-type triterpene saponins from the seeds of tea plant ( $\mathrm{Ca}$ mellia sinensis). Chemical and Pharmaceutical Bulletin 55:57-63.

Zaldibar, B., I. Cancio, M. Soto, I. Marigómez. 2007. Digestive cell turnover in digestive gland epithelium of slugs experimentally exposed to a mixture of cadmium and kerosene. Chemosphere 70:144-154.

Zhong, L., P. Li, J. Han, G. Qu, D. Guo. 2004. Structure-Activity Relationships of Saponins from Gleditsia sinensis in Cytotoxicity and Induction of Apoptosis. Planta Med 70:797-802. 
